\title{
A Rapid Technique for Multiple-race Disease Screening of Phytophthora Foliar Blight on Single Capsicum annuum L. Plants
}

\author{
Ariadna Monroy-Barbosa ${ }^{1}$ and Paul W. Bosland ${ }^{2,3}$ \\ Department of Plant and Environmental Sciences, New Mexico State \\ University, P.O. Box 30003, MSC 3Q, Las Cruces, NM 88003
}

Additional index words. chile pepper, disease resistance, foliar blight screening, physiological races, Phytophthora capsici, plant breeding

\begin{abstract}
Phytophthora blight, caused by the oomycete Phytophthora capsici Leon., is a major disease that threatens production and long-term viability of the chile pepper (Capsicum annuum L.) industry. For each phytophthora disease syndrome such as root rot, foliar blight, and stem blight separate and independent resistant systems have evolved in the host. In addition, several physiological races of the pathogen have been identified. A novel, effective, and accurate screening technique is described that allows for multiple races to be evaluated on a single plant of $C$. annuum. The $P$. capsici resistant line Criollo de Morelos-334, a susceptible cultivar, Camelot, and three New Mexico Recombinant Inbred Lines, -F, -I, -S, were used to evaluate the new technique for phytophthora foliar blight multiple-race screening. Using three $P$. capsici physiological races, no interaction among the physiological races was observed with this technique. This novel technique provided a rapid disease screen evaluating multiple physiological races for phytophthora foliar blight resistance in a single chile pepper plant and can assist plant breeders in selecting for disease-resistant plants.
\end{abstract}

Phytophthora blight caused by the oomycete Phytophthora capsici Leon. is a very destructive disease and was first described attacking chile pepper plants in New Mexico (Leonian, 1922). The pathogen produces several disease syndromes: foliar blight, fruit rot, root rot, and stem blight (Sy et al., 2005); and for the foliar blight, stem blight, and root rot disease syndromes, the resistance is independently inherited (Sy et al., 2005; Walker and Bosland, 1999). In addition, several physiological races of $P$. capsici have been characterized. To date, multiple physiological races for phytophthora root rot and for phytophthora foliar blight syndromes have been reported (Glosier et al., 2008; Oelke et al., 2003; Sy et al., 2008). More recently, race-specific resistance with multiple loci controlling the resistance against the different physiological races of $P$. capsici was reported (Monroy-Barbosa and Bosland, 2008).

Multiple-race inoculation studies in other plant species report both success and failure in inoculating single plants (Geis et al., 1958; Miah and Sackston, 1967; Stavely, 1983). When more than one physiological race or isolate of a pathogen species is inoculated on

Received for publication 22 June 2010. Accepted for publication 6 Aug. 2010.

A contribution of the New Mexico Agr. Expt. Sta., New Mexico State Univ., Las Cruces.

${ }^{1}$ Graduate Research Assistant

${ }^{2}$ Regents Professor.

${ }^{3}$ To whom reprint requests should be addressed; e-mail pbosland@nmsu.edu. a single plant, some researchers report synergistic effects resulting in increased disease symptoms (Maino et al., 1974), the ability of one pathogen enhancing infection and colonization of a second pathogen (Sanogo, 2006), or expression of induced resistance in the host (Kroon et al., 1991; Sidhu and Webster, 1973). Thus, multiple-race screening can make resistant materials appear susceptible, and susceptible plants appear resistant.

Various screening techniques have been developed to evaluate the race-specific resistance pathosystem for the different disease syndromes, i.e., phytophthora root rot screening (Bosland and Lindsey, 1991), foliar blight screening (Alcantara and Bosland, 1994; Oelke et al., 2003), stem blight screening (Sy et al., 2005), and fruit rot screening (Biles et al., 1995). However, earlier published techniques for foliar blight screening produced confounded symptoms between the foliar blight and stem blight in the plant (Fig. 1). The techniques reported lesions in all aerial parts as a symptom of susceptibility (Alcantara and Bosland, 1994; Oelke et al., 2003).

Because it is now known that foliar blight and stem blight are independent and different disease syndromes, a more accurate screening method is required to differentiate foliar blight resistance. Plant breeding for Phytophthora resistance requires the independent evaluation of the different disease syndromes and the different physiological races within the pathogen. This objective can be accomplished with current techniques, but they require a large number of plants, time, space, and resources. To aid in developing new phytophthora blight multirace-resistant chile pepper cultivars, this study describes an effective and rapid screening technique that can determine resistance to multiple physiological races of $P$. capsici foliar blight on a single C. annuum plant.

\section{Materials and Methods}

\section{Plant materials}

The $P$. capsici-resistant line Criollo de Morelos-334 ('CM-334') and a susceptible line, 'Camelot' (Seminis Vegetable Seed, Inc., Oxnard, CA), were used as controls. From the New Mexico Recombinant Inbred Lines (NMRILs) set, three NMRILs, -F, -I, and $-\mathrm{S}$, were selected for inclusion in this study (Sy et al., 2008). The three NMRILs used in this study were selected based on their phenotypic reaction to single $P$. capsici physiological race inoculation. The observed resistant reaction under single physiological race inoculation for the NMRILs were NMRIL-F (resistant to physiological races 1,2, and 4), NMRIL-I (resistant to physiological races 1 and 2; susceptible to physiological race 4), and NMRIL-S (resistant to physiological race 2; susceptible to physiological races 1 and 4).

In the greenhouse, seeds of each line were sown in plastic trays of eight 12-celled containers (T.O. Plastics, Clearwater, MN). Trays were filled with a commercial peatmoss-vermiculite soil mixture (Sun Gro Redi-earth Plug \& Seedling Mix; Sun Gro Horticulture, Bellevue, WA), and they were placed on propagation mats to maintain a $28^{\circ} \mathrm{C}$ soil temperature to promote seed germination. The trays were normally watered twice a day for 2 weeks. The seedlings were transplanted into plastic trays of 18 cells (T.O. Plastics) filled with the same peatmoss-vermiculite soil mixture. The plants were fertilized with a $14 \mathrm{~N}-6.2 \mathrm{P}-11.6 \mathrm{~K}$ slowrelease fertilizer (Scotts, Marysville, $\mathrm{OH}$ ) and were maintained for 2 more weeks until they reached the four- to six-true leaf stage.

\section{Inoculum preparation}

Three isolates of $P$. capsici confirmed as three different foliar blight physiological races (Oelke et al., 2003) were used. These isolates are located at the American Type Culture Collection (ATCC) as physiological race 1 (ATCC no. MYA-2289), race 2 (MYA-2292), and race 4 (MYA-2239). The isolates were maintained separately on water agar plates before use [Bacto agar $(2 \%)$, distilled water $(98 \%)]$ at $24{ }^{\circ} \mathrm{C}$. A $0.5-\mathrm{cm}$ diameter plug was cut from the water agar medium and transferred to V8 juice agar [Bacto agar $(2 \%), \mathrm{CaCO}_{3}(0.3 \%)$, clarified V8 juice (12\%), distilled water (85.7\%)]. The plates were maintained in an incubator at $28^{\circ} \mathrm{C}$ for a period of 4 to $8 \mathrm{~d}$ until numerous sporangia were formed. The V8 agar was cut into 15 to 18 pieces and transferred to $150 \times$ $15-\mathrm{mm}$ petri plates partially filled with sterilized distilled water. The plates were maintained in an incubator for $2 \mathrm{~d}$ at $28{ }^{\circ} \mathrm{C}$. The water plates were incubated at $10^{\circ} \mathrm{C}$ for $1 \mathrm{~h}$ and placed back into the $28{ }^{\circ} \mathrm{C}$ incubator for 
another hour to promote zoospore release. The zoospores were collected and counted using a hemacytometer. The inoculum solution concentration was adjusted to 40,000 zoospores $/ \mathrm{mL}$.

\section{Inoculation method}

From each plant, three mature leaves were selected. A $0.5-\mathrm{cm}$ diameter paper disc made from seed germination paper (Nasco, Modesto, CA) was placed on the surface of each leaf. Using a micropipetter, $50 \mu \mathrm{L}$ of inoculum was placed on each paper disc. The $50 \mu \mathrm{L}$ held $\approx 2000$ zoospores (Fig. 2). The plants were

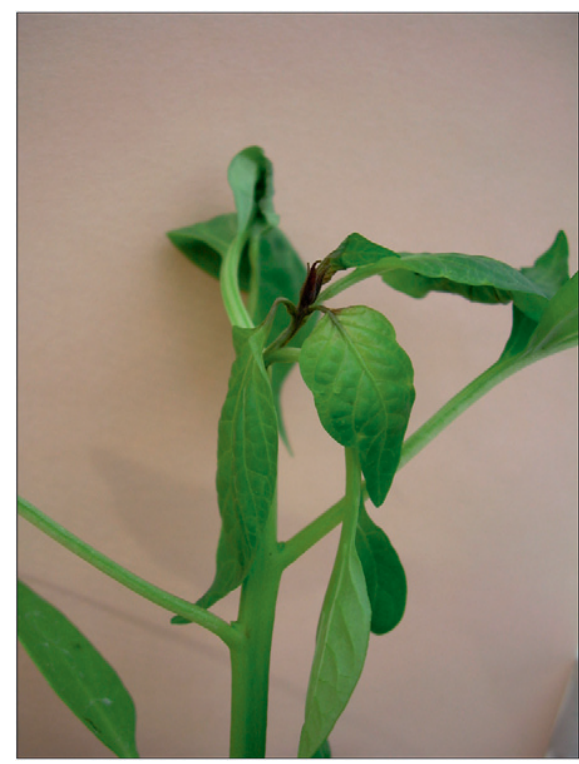

Fig. 1. Confounded symptoms observed in a chile pepper plant under $P$. capsici inoculation using $100 \mu \mathrm{L}$ of 5000 zoospores $/ \mathrm{mL}$.

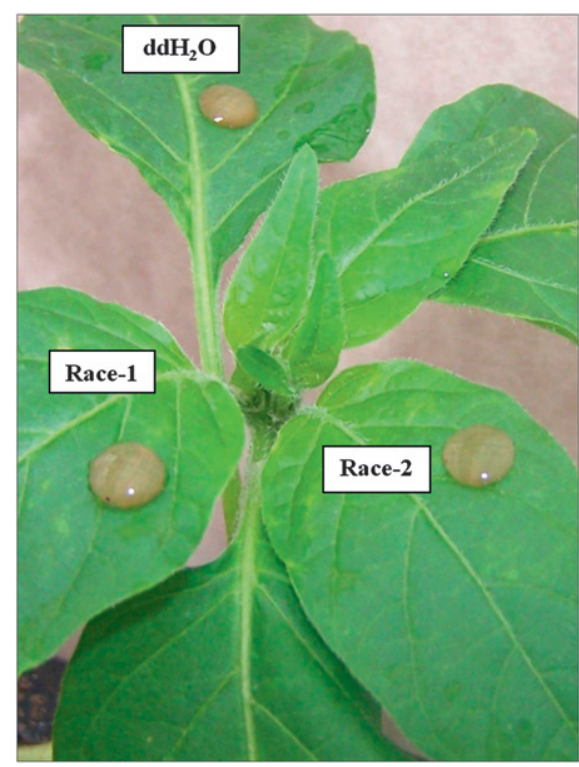

Fig. 2. Inoculation of a New Mexico Recombinant Inbred Line-S plant with $P$. capsici races 1 and $2(50 \mu \mathrm{L}$ of 40,000 zoospores $/ \mathrm{mL})$ and distilled water $\left(\mathrm{ddH}_{2} \mathrm{O}\right)$ using the Phytophthora foliar blight multiple-race screening technique.

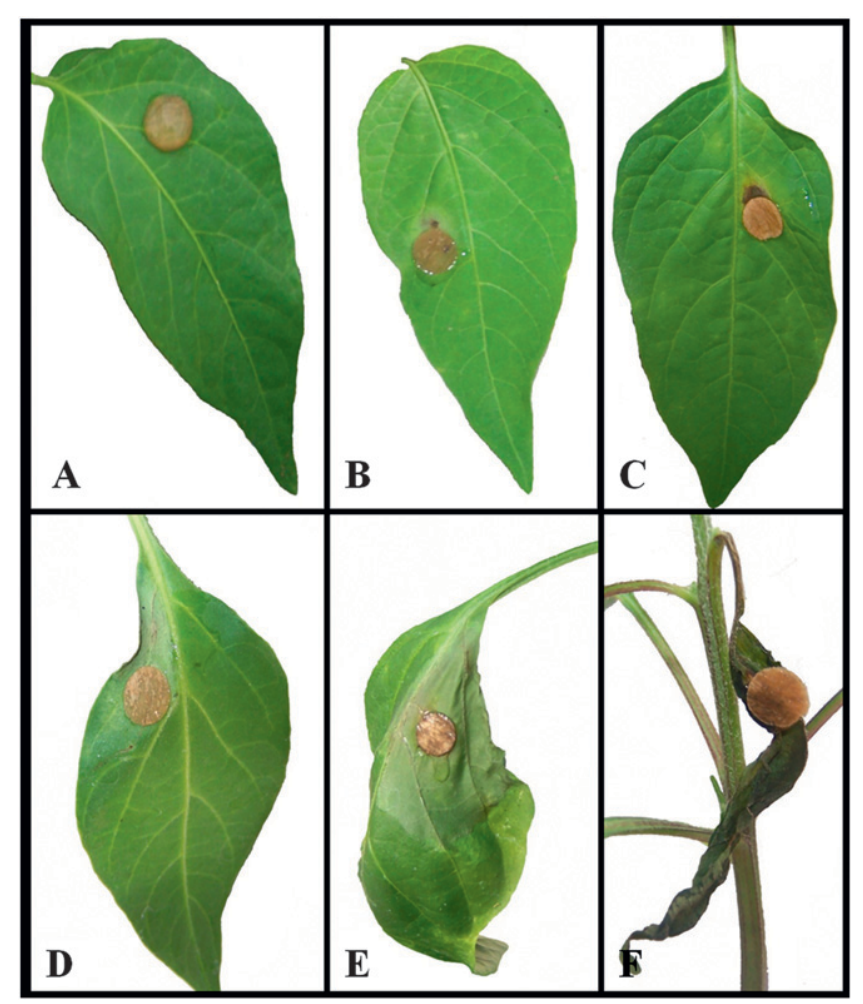

Fig. 3. Disease scale of $P$. capsici foliar blight symptoms produced on C. annuum lines. (A) $0=$ no symptoms; (B) 1 = small lesion under the paper disc area (small, dry spots, with defined borders; lesion associated with hypersensitive response), paper disc was moved from the original place to uncover lesion, discoloration in this leaf is produced by the paper disc; (C) 2 = dark green, water soaked lesion bigger than paper disc area, surrounded by pale yellow undefined borders (paper disc was moved from its original place to show lesion borders); (D) $3=15 \%$ to $49 \%$ of leaf area is wilted (scalded or necrotic); (E) $4=50 \%$ or more of the leaf is wilted; (F) $5=100 \%$ of the leaf is necrotic or the leaf has dropped off from the plant. Leaves scored 0 and 1 are considered resistant. Leaves scored 2 through 5 are considered susceptible. Plants were scored $3 \mathrm{~d}$ after the inoculation.

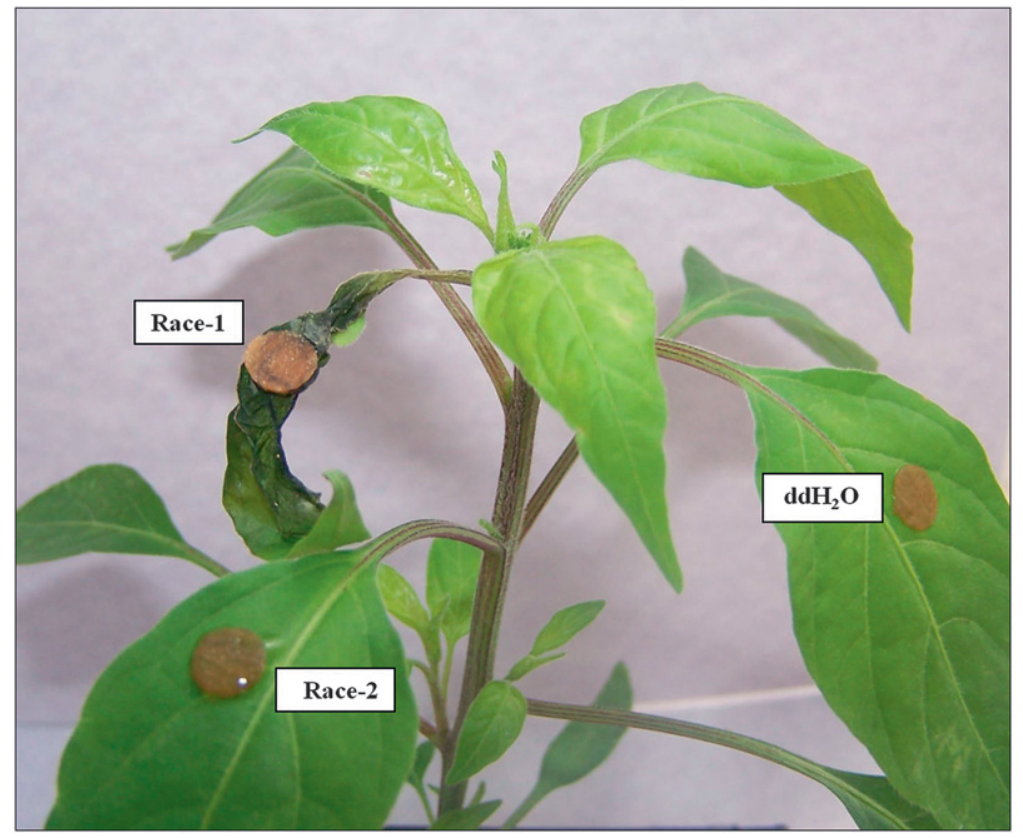

Fig. 4. Phenotypic response of New Mexico Recombinant Inbred Line-S plant $3 \mathrm{~d}$ after inoculation with two P. capsici races 1 and 2 and distilled water $\left(\mathrm{ddH}_{2} \mathrm{O}\right)$ using the Phytophthora foliar blight multiplerace screening technique. 
placed into a mist chamber (Alcantara and Bosland, 1994) with a minimum relative humidity of $70 \%$ and an air temperature of $28{ }^{\circ} \mathrm{C}$. As a control, one of the three paper discs was "inoculated" with distilled water.

\section{Disease screening}

Single physiological race inoculation method. To determine the phenotypic reaction, resistant or susceptible, for the NMRILs and the controls, the accessions were inoculated singularly. A completely randomized design with two replications (different dates) was used. The individual leaf was considered the experimental unit. Using a single Phytophthora isolate, three mature leaves were inoculated per plant with four plants per accession per replication.

Multiple-race inoculation. After the single physiological race inoculation study was accomplished, a multiple-race inoculation study was conducted. A completely randomized design with four replications (different dates) was used. A total of 12 plants of each accession were used per replication. The individual leaf was considered the experimental unit. Three mature leaves per plant were selected. Each leaf was inoculated with a single isolate and each leaf inoculated with a different physiological race (Fig. 2).

\section{Disease scale}

A disease scale was developed to rate the leaf reaction to the interaction of the leaf and the isolate. The scale was $0=$ no symptoms; $1=$ small necrotic tissue with defined borders (associated with hypersensitive response);
$2=$ dark green, water-soaked lesion larger than the paper disc area, surrounded by pale yellow undefined borders; $3=15 \%$ to $49 \%$ of leaf area is wilted, scalded, or necrotic; $4=$ $50 \%$ or more of the leaf is wilted, scalded, or necrotic; and $5=100 \%$ of the leaf is necrotic or the leaf had abscised from the plant (Fig. 3 ). Leaves scored 0 and 1 were rated resistant, whereas leaves scored 2 through 5 were rated susceptible. The plants were observed for symptom development everyday after inoculation with the earliest symptoms appearing $2 \mathrm{~d}$ after inoculation. The plants were removed from the mist chamber, placed on a bench, and scored once the susceptible control ' $\mathrm{Cam}$ elot' displayed a disease assessment level of 5, normally $3 \mathrm{~d}$ after inoculation. Samples of plants with disease assessment scores of each category, 0 to 5 , were maintained in the greenhouse to assess the classification of resistant and susceptible phenotypes. Resistant phenotypes (disease assessment scores of 0 and 1) set fruit, whereas the susceptible phenotypes (disease assessment scores of 2 to 5) died within $60 \mathrm{~d}$ after the inoculation.

\section{Technique evaluation}

The inoculation method was assessed on two factors: precision and accuracy. Precision was based on whether the disease was confined to the foliar region. To be "precise," only the inoculated leaf should show disease symptoms; neither the stem nor the root should have disease symptoms. In addition, the leaf inoculated with distilled water should not show any disease symptom. For accuracy, susceptible and resistant plants should be clearly distinguishable. For the multiple-race inoculation, plants resistant to one, two, or three physiological races should be clearly delineated. Thus, each single leaf should display an independent reaction toward the specific physiological race inoculated. At the same time, the susceptible control should show symptoms to all physiological races tested, whereas the resistant control should not show any symptoms to any of the physiological races inoculated. To evaluate the precision of the multiple screening technique, a comparison between single physiological race inoculation and multiple-race inoculation was made. For each physiological race tested and NMRIL tested, the response should be exactly the same whether a single race or a multiple-race inoculation was done.

\section{Results}

The single physiological race screening technique was $100 \%$ precise and accurate (Table 1). When the three leaves were inoculated with the same physiological race, all leaves displayed the same phenotypic reaction. The resistant control 'CM-334' always displayed a resistant phenotype against all physiological races, scoring 0 in all the disease assessments. The susceptible control, 'Camelot', always displayed a susceptible phenotype scoring 5 in all disease assessments. Leaves inoculated with distilled water did not exhibit any disease symptoms.

When more than one isolate was inoculated on an individual plant, the disease phenotypic reaction did not differ from the

Table 1. Phenotypic response of $C$. annuum recombinant inbred lines inoculated with three $P$. capsici races using a single race inoculation and a multiple-race foliar screening technique.

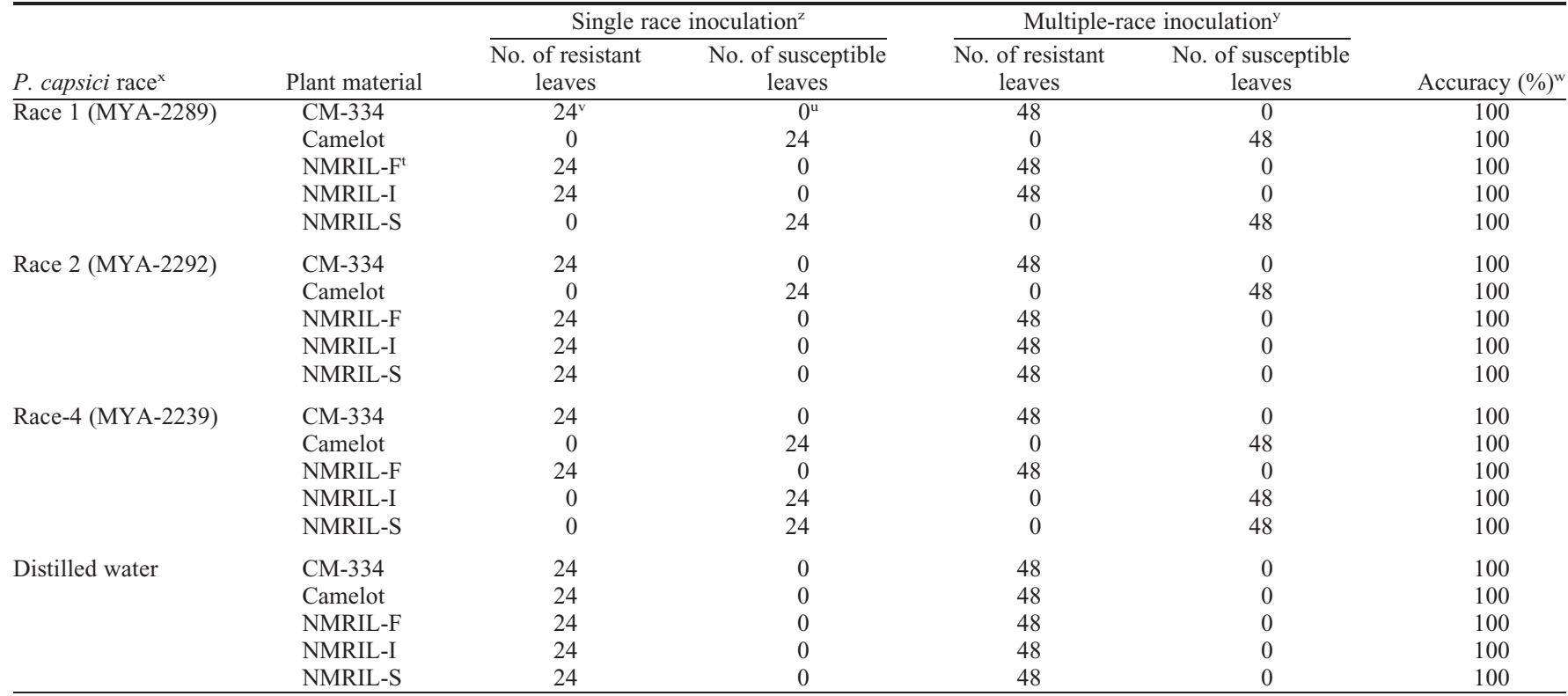

${ }^{2}$ Observed phenotypic reaction on individual leaves using single race foliar inoculation technique.

yPhenotypic reaction observed on individual leaves inoculated using the new multiple-race foliar screening technique.

${ }^{\mathrm{x}}$ Race designation, as determined in Oelke et al. (2003).

${ }^{\mathrm{w}}$ Accuracy for resistant accession $=[$ number of resistant plants/total number of resistant plants $] \times 100$. Accuracy for susceptible accession $=[$ number of susceptible plants/total number of susceptible plants] $\times 100$.

${ }^{\mathrm{v}}$ Resistant phenotype: rated 0 to 1 (no lesions or small, dry spots, with defined borders located under the inoculation area).

uSusceptible phenotype: rated from 2 through 5 (lesion larger than inoculation area with yellow undefined borders, scalded, necrosis, or defoliated leaves).

'New Mexico Recombinant Inbred Line. 
single race inoculation (Table 1 ). The resistant control 'CM-334' did not display any disease symptoms using the multiple-race inoculation technique. The susceptible control 'Camelot' was susceptible to all three physiological races on the same plant.

Each leaf displayed race-specific resistance to the specific physiological race inoculated. For example, NMRIL-I displayed resistance to physiological races 1 and 2 and susceptibility to physiological race 4 , which are the same results obtained with the single physiological race inoculations. When NMRIL$\mathrm{S}$ was challenged with the three physiological races, it was resistant to physiological race 2 and susceptible to physiological races 1 and 4 . These are the same disease assessment results as with the single physiological race inoculation. When NMRIL-F was challenged with all three physiological races, it was resistant to all three physiological races, again like with the single physiological race inoculation.

Statistical analysis was not performed nor was it necessary because the results had an absolute association between the single and the multiple-race screening.

\section{Discussion}

An important goal in breeding chile peppers for disease resistance is to screen plants for resistance to several physiological races of $P$. capsici. Generally, individual plants are inoculated with only one isolate, requiring a large number of plants and resources (Alcantara and Bosland, 1994; Oelke et al., 2003). This study provided a screening technique that allows for several physiological races of $P$. capsici to be evaluated on a single chile pepper plant. This technique reduces the number of plants necessary to screen for foliar blight resistance. Another outstanding feature of this novel technique is that the plants can be scored in only $3 \mathrm{~d}$ after inoculation.

The novel screening technique described in this study was successful in differentiating between susceptible and resistant plants for the phytophthora foliar blight syndrome. The new technique was $100 \%$ precise in that only the inoculated leaves displayed disease symptoms. At scoring time, no other plant organs, i.e., stems, apical meristems, or roots, displayed disease symptoms (Fig. 4). When after disease scoring, the resistant plants (disease assessment level of 0 and 1) were removed from the mist chamber and maintained for an additional $60 \mathrm{~d}$ in the greenhouse, no other plant organ showed phytophthora blight/ rot symptoms. Any plant recording a disease score of 0 or 1 survived to set fruit. Any plant scoring a disease assessment score of 2 to 5 did not set fruit; in fact, they exhibited defoliation or died. In this study, NMRIL-I, NMRIL-S, and the susceptible control inoculated with multiple races did not reach the fruiting stage. The plants were susceptible to at least one of the physiological races. Thus, the disease spread from the susceptible leaf to the main stem killing the plant. Only NMRIL-F and 'CM-334' were able to survive because of their resistance and they set fruits. The use of the paper disc prevented runoff of the inoculum toward the stems and the roots. Therefore, root rot and stem blight disease symptoms did not confound the screening results, which was one of the main issues with the foliar blight screening techniques used in the past (Alcantara and Bosland, 1994; Oelke et al., 2003). An application of 2000 zoospores per leaf provided excellent differentiation between resistant and susceptible genotypes (Table 1).

When leaves of an individual NMRIL plant were inoculated with different physiological races of $P$. capsici, no change in the expression of resistance or susceptibility was observed. Each leaf displayed the same reaction in the multiple-race inoculation as displayed using the single race inoculation method (Table 1). This new screening technique facilitates screening for phytophthora foliar blight resistance, enabling researchers to test a given plant for a range of resistance genes/alleles in the individual plant.

Based on the gene-for-gene theory, the resistance expression depends on the compatibility between the host and a specific pathogen race (Flor, 1947). Being able to identify which specific resistance genes are in a single chile pepper plant will significantly increase the efficiency of breeding for resistant cultivars. Identification of resistant genes to different physiological races provides important information for pyramiding resistance genes in a chile pepper cultivar. The screening technique will also be useful when the physiological race of a $P$. capsici isolate needs to be identified. The new technique has been incorporated into the New Mexico State University chile pepper breeding program enabling rapid screening of a large number of breeding accessions for phytophthora foliar blight resistance.

\section{Literature Cited}

Alcantara, T.P. and P.W. Bosland. 1994. An inexpensive disease screening technique for foliar blight of chile pepper seedlings. HortScience 29:1182-1183.

Biles, C., B.D. Bruton, M.M. Wall, and M. Rivas. 1995. Phytophthora capsici zoospore infection of pepper fruit in various physical environments. Proc. Okla. Acad. Sci. 75:1-5.

Bosland, P.W. and D.L. Lindsey. 1991. A seedling screen for Phytophthora root rot of pepper, Capsicum annuum. Plant Dis. 75:1048-1050.

Flor, H.H. 1947. Inheritance of reaction to rust in flax. J. Agr. Res. 74:241-262.

Geis, J.R., M.C. Futrell, and W.N. Garrett. 1958. A method for inoculating single wheat leaves with more than one race of Puccinia graminis f, sp. tritici. Phytopathology 48:387-388.

Glosier, B.R., E.A. Ogundiwin, G.S. Sidhu, D.R. Sischo, and J.P. Prince. 2008. A differential series of pepper (Capsicum annuum) lines delineates fourteen physiological races of Phytophthora capsici. Euphytica 162:23-30.

Kroon, B.A.M., R.J. Scheffer, and D.M. Elgersma. 1991. Induced resistance in tomato plants against fusarium wilt invoked by Fusarium oxysporum f. sp. dianthi. Neth. J. Pl. Path. 97: 401-408.

Leonian, L.H. 1922. Stem and fruit blight of peppers caused by Phytophthora capsici. Phytopathology 12:401-408.

Maino, A.L., M.N. Schroth, and V.B. Vitanza. 1974. Synergy between Achromobacter sp. and Pseudomonas phaseolicola resulting in increased disease. Phytopathology 64:277-283.

Miah, M.A.J. and W.E. Sackston. 1967. A simple method for inoculating individual leaves of sunflowers and wheat with several races of rust. Phytopathology 57:1396-1397.

Monroy-Barbosa, A. and P.W. Bosland. 2008. Genetic analysis of Phytophthora root rot racespecific resistance in chile pepper. J. Amer. Hort. Soc. 133:825-829.

Oelke, L.M., P.W. Bosland, and R. Steiner. 2003. Differentiation of race specific resistance to Phytophthora root rot and foliar blight in Capsicum annuиm. J. Amer. Soc. Hort. Sci. 128: 213-218.

Sanogo, S. 2006. Interactive effects of two soilborne pathogens, Phytophthora capsici and Verticillium dahliae, on chile pepper. Phytopathology 97:37-43.

Sidhu, G.S. and J.M. Webster. 1973. Genetics of tomato resistance to the fusarium-verticillium complex. Physiological Plt. Path. 15:93-98.

Stavely, J.R. 1983. A rapid technique for inoculation of Phaseolus vulgaris with multiple pathotypes of Uromyces phaseoli. Phytopathology 73:676-679.

Sy, O., R. Steiner, and P.W. Bosland. 2005. Inheritance of Phytophthora stem blight resistance as compared to Phytophthora root rot and Phytophthora foliar blight resistance in Capsicum annuum L. J. Amer. Hort. Soc. 130: 75-78.

Sy, O., R. Steiner, and P.W. Bosland. 2008. Recombinant inbred line differential identifies race-specific resistance to Phytophthora root rot in Capsicum annuum. Phytopathology 98: 867-870.

Walker, S.J., and P.W. Bosland. 1999. Inheritance of Phytophthora root rot and foliar blight resistance in pepper. J. Amer. Soc. Hort. Sci. 124:14-18. 